Araştırma Makalesi/Research Article

\title{
Palandöken Dağı Korunan Bir Alpin Meranın Bitki Örtüsü, Yaygın Geniş Yapraklı Türlerin Yersel Dağılımı ve Bitki Türleri İle Toprak Özellikleri Arasındaki İlişkiler
}

\author{
Şule Erkovan* iD Ali Koç \\ Eskişehir Osmangazi Üniversitesi, Ziraat Fakültesi, Tarla Bitkileri Bölümü, Eskişehirișpeps \\ *Sorumlu yazar: serkovan@ogu.edu.tr
}

Geliş Tarihi: 24.02 .2021

Kabul Tarihi: 06.05.2021

Öz

Canlı ve dinamik yapıya sahip mera vejetasyonları çok çeşitli faktörlerin etkisi altında şekillenmektedir. Yüksek rakıma sahip korunan mera alanında yürütülen bu çalışmada toplam 47 bitki türüne rastlanılmış, buğdaygiller familyasına dahil türlerin oranı 40,90, baklagiller familyasına dahil türlerin oranı 36,31 ve diğer familyalara dahil türlerin oranı 22,80 olarak bulunmuştur. Yersel değişkenlik homojen olmayan bir dağılım göstermiş, en homojen dağılım Medicago papillosa olduğu belirlenmiştir. Bitki türleri ve toprak özellikleri arasında önemli ilişskiler tespit edilmiştir. Buğdaygil türleri ordinasyon ekseninde merkezde yer alırken, diğer türler toprak özelliklerine bağlı olarak eksenlere dağılmıştır. Sonuç olarak korunan mera vejetasyonlarında otlatmanın olumsuz etkisi olmamasına karşın bitkiler arası ve bitki çevre ilişkilerinin önemli olduğu belirlenmiştir.

Anahtar Kelimeler: Botanik kompozisyon, yersel dağılım, bitki toprak ilişkileri

\section{Vegetation of an Enclosed Alpine Rangeland of Palandoken Mountain, Spatial Distribution of Common Forb Species, and Relations Among the Plant Species and Soil Characteristics}

Rangeland vegetation, which have active and dynamic structures, are formed under the effect of various factors. Totally 47 plant species were detected and 40,90\% of them were grass species, 36,31\% were legume species, and the $22,80 \%$ of it were constituted of the other species. Spatial distribution of the species were determined as fragmental and Medicago papillosa was the most homogenous among the species. Significant relations were determined among the plant species and soil characteristics. While grass species were located at the center, other species dispersed through the axis according to the ordination analysis that conducted based on the soil characteristics. Results showed that despite the negative effect of the grazing did not exist, plant-plant and plant-environment relations could significantly affect the vegetation in enclosed rangelands.

Keywords: Botanical composition, spatial patterns, plant and soil relationships

\section{Giriş}

Meralar hayvanlara yem üretmenin yanı sıra toprak ve su muhafazası, doğanın korunması ve güzelleşmesi gibi pek çok fonksiyonları vardır. Hayvancılığın temel yem kaynağı olan meralar, dünyada çiftlik hayvanların ihtiyaç duyduğu kaba yemin yaklaşık \%70'ini karşılamaktadır (Lund, 2007). Bununla birlikte toprak yüzeyini kaplayarak toprakların yerinde tutulmasını ve yağış sularının toprağa infiltre olmasını sağlamak suretiyle erozyonu azaltmaktadırlar. Ayrıca yeşil renk maddesinden dolayı $\mathrm{O}_{2}$ üretimi, renk çeşitliliğinden dolayı görünüm ve mesire yeri, yaban hayatı ve arıcılık için biyoçeşitlilik gibi avantajlar sağlamaktadır (Altın ve ark. 2011).

Mera bitki örtüleri canlı ve dinamik bir yapıya sahip olup çok sayıda türden meydana gelmektedir. Meralarda baskın türler buğdaygiller familyasına dahil türler olmasına rağmen farklı familyalara ait türler önemli rol oynamaktadırlar. Çünkü hem aynı türler arasında hem de farklı türler arasında etkileşim bulunmaktadır. Türler arasındaki bu etkileşim bitki örtüsü, iklim, çevre ve kullanım şartlarındaki değişimler tarafından şekillenmektedir. Bitki türleri arasında stresin olumsuz etkisini hafifletmek amacıyla türler arasında pozitif bir etkileşimin olduğu bilinmektedir (Cramer ve ark. 2010; 
Grant ve ark. 2014). Ancak stres şartları ortadan kalktığında pozitif etki negatif, olumsuz veya rekabet olarak adlandırılan etkiye dönüşmektedir (Castanho ve ark. 2015). Olumlu veya olumsuz ilişkiler toplulukların oluşması, canlılığı ve yok olmasında çok önemli role sahiptir (Verdu ve ark. 2010).

Bitkilerin gelişimi ve tür kompozisyonu üzerine komşu bitki türlerinin etkileri tam olarak bilinmemektedir. Olumsuz çevre şartlarını iyileştirmede azot bağlayan bitkiler doğrudan veya dolaylı olarak pozitif yönde etkilemektedir (Kurokawa et al. 2010). Bu durum bitki örtüsünün tür bileşeninin şekillenmesinde etkili olmaktadır. Örneğin bozulmuş alanlarda baklagillerin yoğunluğu artarak ortamın iyileşmesine katk1 sağlamakta (Venterink 2011) ve zamanla diğer bitkilerin ortama yerleşmesine öncülük etmektedir. Doğal bitki örtülerini meydana getiren türler arasındaki karşılıklı ilişkilerin bilinmesi bitki örtüsünün tür bileşeninin değişim yönü hakkında fikir verecektir. Bu bilgiler etkin bir şekilde değerlendirilerek değişim yönüne müdahale etmek mümkündür. Elde edilen bilgiler doğrultusunda otlatmanın düzenlenmesi veya uygun ıslah yöntemleri (gübreleme, üstten tohumlama, temizlik biçimi vb) ile bitki örtüsünün amaca uygun (otlatma için daha fazla üretim sağlanabileceği gibi türlerin korunması ve bitki örtüsünde çeşitliliğin muhafazası) bir şekilde yöneliminin sağlanmas1 mümkün olabilir. $\mathrm{Bu}$ sayede ekosistemin işlevlerini sağlıklı bir şekilde sürdürebilmesine katkı sağlayacaktır.

Palandöken Dağlarında yüksek rakımlı (alpin) bir merada yürütülen bu çalışmanın amacı korunan mera alanlarında; I. botanik kompozisyonu belirlemek, II. kompozisyonda yaygın olan geniş yapraklı türlerin yersel dağılımını ortaya çıkarmak ve III. tür bileşeninde oranları \%1'den daha fazla olan türlerin toprak özellikleri ile ilişkilerini belirlemektir.

\section{Materyal ve Metod}

Araștırma Erzurum ili Palandöken Dağlarında 2250 m rakıma ve \%20 eğime sahip korunan mera alanında 2013 ve 2014 yıllarında iki yıl süre ile yürütülmüştür. Vejetasyon etüdü mera alanındaki bitki türlerinin teşhislerinin yapılabilmesi için baskın türlerin çiçeklendiği dönemde (Haziran) yapılmıştır. Botanik kompozisyonu belirlemek için bitki örtüsünün yüzeysel değişimi dikkate alınarak eğime dik bir şekilde (kuzey-güney istikametinde) modifiye edilmiş tekerlekli nokta metodu ile 10 hatta toplam 1000 noktada bitki örneklemesi yapılmıştır. Her bitki türüne ait değerler toplam bitki sayısına oranlanarak türlerin botanik kompozisyondaki oranları hesaplanmıştır (Gökkuş ve ark. 1995).

Yüksek rakım ve karasal iklimin hüküm sürdüğü ilde gece-gündüz ve yaz-kıș arasında büyük sıcaklık farklılıkları görülmektedir. Kışlar soğuk ve kar yağışlı, yazlar serin ve kurak geçmektedir. Yağışlar daha çok kış ve ilkbahar aylarında düşmektedir. Uzun yıllar ortalaması yıllık toplam yağış $391,6 \mathrm{~mm}, 2013$ ve 2014 yıllarında toplam yağış miktarları sırasıyla 284,4 ve 419,5 mm olarak kaydedilmiştir. Uzun yıllar ortalamas $5,1^{\circ} \mathrm{C}$ olan sicaklık, 2013 yılında $5,3^{\circ} \mathrm{C}, 2014$ yılında ise $7,7^{\circ} \mathrm{C}$ olarak kaydedilmiştir. Nispi nem uzun yıllar ortalaması olarak \%66,4 olarak kaydedilmiş, 2013 yılında uzun yıllar ortalamasının üzerinde $(\% 66,0), 2014$ yılında ise uzun yıllar ortalamasının altında $(\% 63,8)$ olmuştur (Çizelge 1) (Anonim, 2015). Mera alanında alınan topraklar tınlı bünyeye sahip olup, pH 6,17 , organik madde $\% 6,59$, agregat stabilitesi \%82, 40, elektriksel iletkenlik 244,02 $\mu \mathrm{mhos} / \mathrm{cm}, 9,47$ $\mathrm{kg} / \mathrm{da} \mathrm{P}_{2} \mathrm{O}_{5}$ ve $0,39 \% \mathrm{CaCO}_{3}$ olarak tespit edilmiştir (Soil Survey Laboratory Staff, 1992).

Yapılan vejetasyon etüdünde Medicago papillosa, Astragalus microcephalus, Thymus parviflorus ve Hypericum scabrum türlerinin X-Y düzleminde kuzey-güney istikametinde varlıkları kaydedilmiştir. Kaydedilen veriler kullanılarak türlerin yersel dağılımları GS + geostatistical software ile belirlenmiştir (Gamma Design Software, 2005).

Bitki örtüsü ile toprak özellikleri arasındaki ilişki multivaryete istatistik metotlarından ordinasyon analizi CANOCO 4.5 for Windows programı kullanılarak belirlenmiştir. Multivaryete analizde CCA (Canonical Correspondance Analysis) yöntemi kullanılmıştır (ter Braak ve Smilauer, 2002). İncelenen mera vejetasyonunda bitki türlerinin oranı \%1'in altında kalanlar ordinasyon analizine dahil edilmemiştir. 
Çizelge 1. Araştırma sahasının 2013 ve 2014 yılları ile uzun yıllar (1990-2014) ortalamasına ait yağış, sıcaklık ve nispi nem değerleri (Anonim, 2015)

\begin{tabular}{|c|c|c|c|c|c|c|c|c|c|}
\hline \multirow[t]{2}{*}{ Aylar } & \multicolumn{3}{|c|}{$\begin{array}{l}\text { Aylık Toplam Yağış } \\
\text { (mm) }\end{array}$} & \multicolumn{3}{|c|}{$\begin{array}{l}\text { Aylık Ortalama Sicaklık } \\
\qquad\left({ }^{0} \mathrm{C}\right)\end{array}$} & \multicolumn{3}{|c|}{$\begin{array}{c}\text { Aylık Ortalama Nispi } \\
\text { Nem }(\%)\end{array}$} \\
\hline & 2013 & 2014 & Ort & 2013 & 2014 & Ort & 2013 & 2014 & Ort \\
\hline Ocak & 28,7 & 11,3 & 16,5 & $-9,5$ & $-10,1$ & $-10,6$ & 83,0 & 83,9 & 78,8 \\
\hline Șubat & 28,5 & 8,0 & 20,3 & $-7,4$ & $-4,5$ & $-9,1$ & 89,5 & 80,4 & 78,2 \\
\hline Mart & 30,9 & 47,1 & 35,5 & $-0,8$ & 2,7 & $-2,5$ & 75,9 & 65,0 & 74,9 \\
\hline Nisan & 36,3 & 34,0 & 58,1 & 7,2 & 7,7 & 5,4 & 64,4 & 61,0 & 67,6 \\
\hline May1s & 36,3 & 115,9 & 67,5 & 11,6 & 11,7 & 10,5 & 63,5 & 64,8 & 64,0 \\
\hline Haziran & 32,3 & 24,5 & 40,9 & 15,0 & 15,9 & 14,9 & 57,2 & 50,6 & 58,7 \\
\hline Temmuz & 25,1 & 44,7 & 25,3 & 19,4 & 21,2 & 19,2 & 50,4 & 44,1 & 53,2 \\
\hline Ağustos & 7,8 & 4,8 & 14,1 & 19,5 & 22,2 & 19,4 & 45,9 & 37,2 & 50,2 \\
\hline Eylül & 13,6 & 47,7 & 21,0 & 13,6 & 15,4 & 13,9 & 49,8 & 48,3 & 52,4 \\
\hline Ekim & 16,8 & 51,6 & 43,3 & 6,0 & 8,8 & 7,7 & 59,6 & 67,4 & 65,3 \\
\hline Kasım & 19,6 & 17,2 & 27,4 & 2,3 & 1,3 & 0,0 & 74,1 & 68,5 & 73,7 \\
\hline Aralık & 8,3 & 12,7 & 21,8 & $-13,4$ & $-0,2$ & $-7,2$ & 78,6 & 81,5 & 79,3 \\
\hline Top/Ort & 284,2 & 419,5 & 391,6 & 5,3 & 7,7 & 5,1 & 66,0 & $\begin{array}{l}63,8 \\
\end{array}$ & 66,4 \\
\hline
\end{tabular}

\section{Bulgular ve Tartışma}

\section{Botanik Kompozisyon}

Botanik kompozisyonda ortalama \%40,90 olan buğdaygillerin oranı birinci yı1 \%45,03, ikinci yı1 \%36,77 olarak kaydedilmiştir. Ortalama \%36,31 ola baklagillerin oranı ilk ve ikinci yılda \%33,91 ve $\% 38,70$, diğer familyalara ait türlerin oranı (ortalama \%22,80) ise yıllara göre \%21,06 ve \%24,53 olmuştur (Çizelge 2). Buğdaygiller familyasına dahil türlerden Festuca ovina (\%16,81), Bromus variegatus $(\% 15,38)$, Phleum montanum $(\% 5,13)$ ve Koeleria cristata $(\% 2,53)$, baklagillerden Medicago papillosa $(\% 20,05)$, Astragalus lineatus $(\% 10,65)$ ve Astragalus microcephalus $(\% 5,08)$ ve diğer familyalardan ise Thymus parviflorus (\%6,70), Alyssum desertorum $(\% 1,16)$, Dianthus multicaulis (\%1,14), Galium verum (\%1,75), Hypericum scabrum (\%1,64), Plantago lanceolata $(\% 1,39)$ ve Ziziphora persica $(\% 1,12)$ türlerine botanik kompozisyonda \%1'in üzerinde rastlanmıştır (Çizelge 2).

Buğdaygiller familyasına dahil bitki türleri meraların hakim bitki türleridir (Herbel ve Pieper, 1991). Buğdaygiller yüzeysel ve yoğun dallanan saçak kökleri sayesinde toprak yüzeyini nemlendiren kısa süreli az yağışları en etkili değerlendiren bitki türleridir (Lauenroth, 1979). Bu özellikleri dünya meralarında buğdaygillerin hakim tür olmasında etkili olmaktadır. Buğdaygiller familyasına dahil türlerin oranının kompozisyonda yüksek olmasının bir başka nedeni ise rekabet güçlerinin yüksek olmasıdır. Rekabet gücü yüksek olan bitki türleri ortam faktörlerini diğer türlere göre daha iyi değerlendirmektedirler (Erkovan ve ark. 2008; Erkovan ve ark. 2011). Başka bir ifadeyle yağışın mevsimsel değişimi türlerin oranının değişimine etki eden en önemli faktörlerdendir (Clarke ve ark. 2005). Çalışmanın yürütüldüğü mera kesiminde buğdaygiller familyasına dahil bitki türlerinin oranının ikinci yılda azalmasının iklim seyrindeki farklılık ile ilgili olması muhtemeldir. Büyüme mevsimi içerisinde düşen yağışlar saçak köklü türlerin oranını artırırken, sonbahar ve kışın düşen yağışlar derine sızacağı için kazık köklü türlerin oranlarını artırmaktadır (Friedel ve ark. 1993). İkinci yılda Mayıs ayı uzun yıllar ortalamasının üzerinde yağış almakla birlikte büyüme mevsimine denk gelen yıllarda uzun yıllar ortalamasına göre daha az yağış düşmüştür (Çizelge 1). Bu durum ikinci yılda kazık köklü bitkilerde gelişmeyi teşvik ettiği için tür bileşeninde baklagillerin oranı artış göstermiştir. 
Çizelge 2. Araştırma sahasına ait bitki türleri, kısaltmaları ve yıllara göre botanik kompozisyondaki oranları (\%)

\begin{tabular}{|c|c|c|c|c|}
\hline $\begin{array}{l}\text { Bitki Türleri } \\
\text { Buğdaygiller }\end{array}$ & Kisaltmalar & 2013 & 2014 & Ort \\
\hline Bromus variegatus & BroVar & 17,66 & 13,10 & 15,38 \\
\hline Bromus lanceolatus & BroLan & - & 0,33 & 0,17 \\
\hline Bromus tomentellus & BroTom & - & 0,79 & 0,40 \\
\hline Dactylis glomerata & DacGlo & 0,12 & - & 0,06 \\
\hline Festuca oreophila & FesOre & 0,66 & - & 0,33 \\
\hline Festuca ovina & FesOvi & 19,41 & 14,21 & 16,81 \\
\hline Koeleria cristata & KoeCri & 1,93 & 3,12 & 2,53 \\
\hline Phleum montanum & PhlMon & 5,15 & 5,10 & 5,13 \\
\hline Poa bulbosa & PoaBul & 0,10 & 0,12 & 0,11 \\
\hline Toplam & & 45,03 & 36,77 & 40,90 \\
\hline \multicolumn{5}{|l|}{ Baklagiller } \\
\hline Astragalus microcephalus & AstMic & 3,68 & 6,48 & 5,08 \\
\hline Astragalus lagurus & AstLag & - & 0,85 & 0,43 \\
\hline Astragalus lineatus & AstLin & 9,89 & 11,41 & 10,65 \\
\hline Coronilla orientalis & CorOri & 0,21 & - & 0,10 \\
\hline Medicago papillosa & MedPap & 20,13 & 19,96 & 20,05 \\
\hline Toplam & & 33,91 & 38,70 & 36,31 \\
\hline \multicolumn{5}{|l|}{ Diğer Familyalar } \\
\hline Acantholimon caryophyllaceum & AcaCar & 0,47 & 0,23 & 0,35 \\
\hline Achillea millefolium & AchMil & 0,85 & 0,65 & 0,75 \\
\hline Achillea biebersteinii & AchBie & - & 0,23 & 0,11 \\
\hline Alyssum desertorum & AlyDes & - & 2,31 & 1,16 \\
\hline Alyssum murale & AlyMur & 0,83 & 0,33 & 0,58 \\
\hline Carum carvii & CarCar & - & 0,22 & 0,11 \\
\hline Campanula stevenii & CamSte & - & 0,56 & 0,28 \\
\hline Campanula rapunculoides & CamRap & 0,12 & - & 0,06 \\
\hline Carex distans & CarDis & 0,36 & - & 0,18 \\
\hline Centaurea sessilis & CenSes & 0,26 & 0,54 & 0,40 \\
\hline Centaurea urvillei & CenUrv & 0,12 & 0,21 & 0,17 \\
\hline Dianthus multicaulis & DiaMul & 1,08 & 1,19 & 1,14 \\
\hline Galium incanum & GalInc & 0,22 & - & 0,11 \\
\hline Galium verum & GalVer & 1,65 & 1,85 & 1,75 \\
\hline Helichrysum arenarium & HelAre & 0,12 & 0,22 & 0,17 \\
\hline Hypericum scabrum & HypSca & 2,28 & 1,00 & 1,64 \\
\hline Muscari massayanum & MusMas & - & 0,22 & 0,22 \\
\hline Onosma sp & Onosma & - & 0,68 & 0,34 \\
\hline Plantago lanceolata & PlaLan & 1,54 & 1,23 & 1,39 \\
\hline Polygonum cognatum & PolCog & 0,57 & 1,19 & 0,88 \\
\hline Potentilla recta & PotRec & 0,96 & - & 0,48 \\
\hline Rumex acetocella & RumAce & - & 0,12 & 0,06 \\
\hline Sedum subulatum & SedSub & 0,58 & 0,21 & 0,40 \\
\hline Silene alba & SilAlb & 0,36 & 0,87 & 0,62 \\
\hline Stachys lavandulifolia & StaLav & 0,11 & - & 0,06 \\
\hline Tanacetum abrotanifolium & TanAbr & - & 0,10 & 0,05 \\
\hline Taraxacum officinalis & TarOff & - & 0,33 & 0,17 \\
\hline Teucrium polium & TeuPol & 0,24 & 0,52 & 0,38 \\
\hline Thymus parviflorus & ThyPar & 6,14 & 7,26 & 6,70 \\
\hline Tragopogon reticulatus & TraRet & 0,24 & 0,33 & 0,29 \\
\hline Verbascum cheiranthifolium & VerChe & 0,67 & 0,65 & 0,66 \\
\hline Veronica orientalis & VerOri & 0,11 & 0,22 & 0,16 \\
\hline Ziziphora persica & ZizPer & 1,17 & 1,06 & 1,12 \\
\hline Toplam & & 21,06 & 24,53 & 22,80 \\
\hline
\end{tabular}

Türlerin Yersel Dağılımı

Yöneysel semivariogramların yapısal değerleri arasında farklılıklar olmadığ 1 için yersel 
değişkenliği tanımlamak amacıyla isotropik semivariogram modelleri en uygun modeller olarak seçilmiştir. $M$. papillosa ve $H$. scabrum için exponensiyal, A. microcephalus ve $T$. parviflorus için küresel semivariogram modellerinin uygun modeller olduğu tespit edilmiştir (Çizelge 3). Yersel bağımlılık derecelerinin $\% 6,98$ ile $\% 18,52$ arasında değiştiği, bitki türlerinin çok güçlü yersel bağımlılık gösterdikleri belirlenmiştir. Etki aralığı mesafeleri $17,01 \mathrm{~m}, 36,00 \mathrm{~m}, 18,02 \mathrm{~m}$ ve $15,30 \mathrm{~m}$ olup, en yüksek etki mesafesi $M$. papillosa $(36,00 \mathrm{~m})$ bitkisinde tespit edilmiştir. Bu durum $M$. papillosa'nın daha homojen bir dağılım gösterdiğine dikkat çekmektedir. A. eriocephalus rastgele bir dağılım sergilemiş, T. parviflorus kuzey batı kesiminde yoğunluk göstermiş, en düşük etki mesafesine sahip tür H. scabrum (15,30 m) olup diğer türlere oranla daha seyrek dağglım sergilemiştir (Şekil 1).

Çizelge 3. Geniş yapraklı bitki türlerinin mera vejetasyonlarında batı (x) kuzey (y) ekseninde yersel dağılımları

\begin{tabular}{lcccccc}
\hline \multicolumn{1}{c}{ Bitki türleri } & $\begin{array}{c}\text { Semivariogram } \\
\text { model }\end{array}$ & $\mathrm{C}_{0}$ & $\mathrm{C}_{0}+\mathrm{C}$ & $\mathrm{C}_{0} / \mathrm{C}_{0}+\mathrm{C}$ & $\mathrm{A}_{0}$ & $\mathrm{r}^{2}$ \\
\hline M. papillosa & Küresel & 0,086 & 1,232 & 6,98 & 17,01 & 0,255 \\
A. microcephalus & Exponensiyal & 0,770 & 4,157 & 18,52 & 36,00 & 0,904 \\
T. parviflorus & Küresel & 0,070 & 0,924 & 7,58 & 18,02 & 0,845 \\
H. scabrum & Exponensiyal & 0,0316 & 0,3242 & 9,75 & 15,30 & 0,211 \\
\hline
\end{tabular}

$\mathrm{C}_{0}$ : Nugget varyans1, $\mathrm{C}_{0}+\mathrm{C}$ :Sill varyans1, $\mathrm{C}_{0} \mathrm{C}_{0}+\mathrm{C}$ : Nugget/Still, $\mathrm{A}_{0}$ : Etki aralığ 1
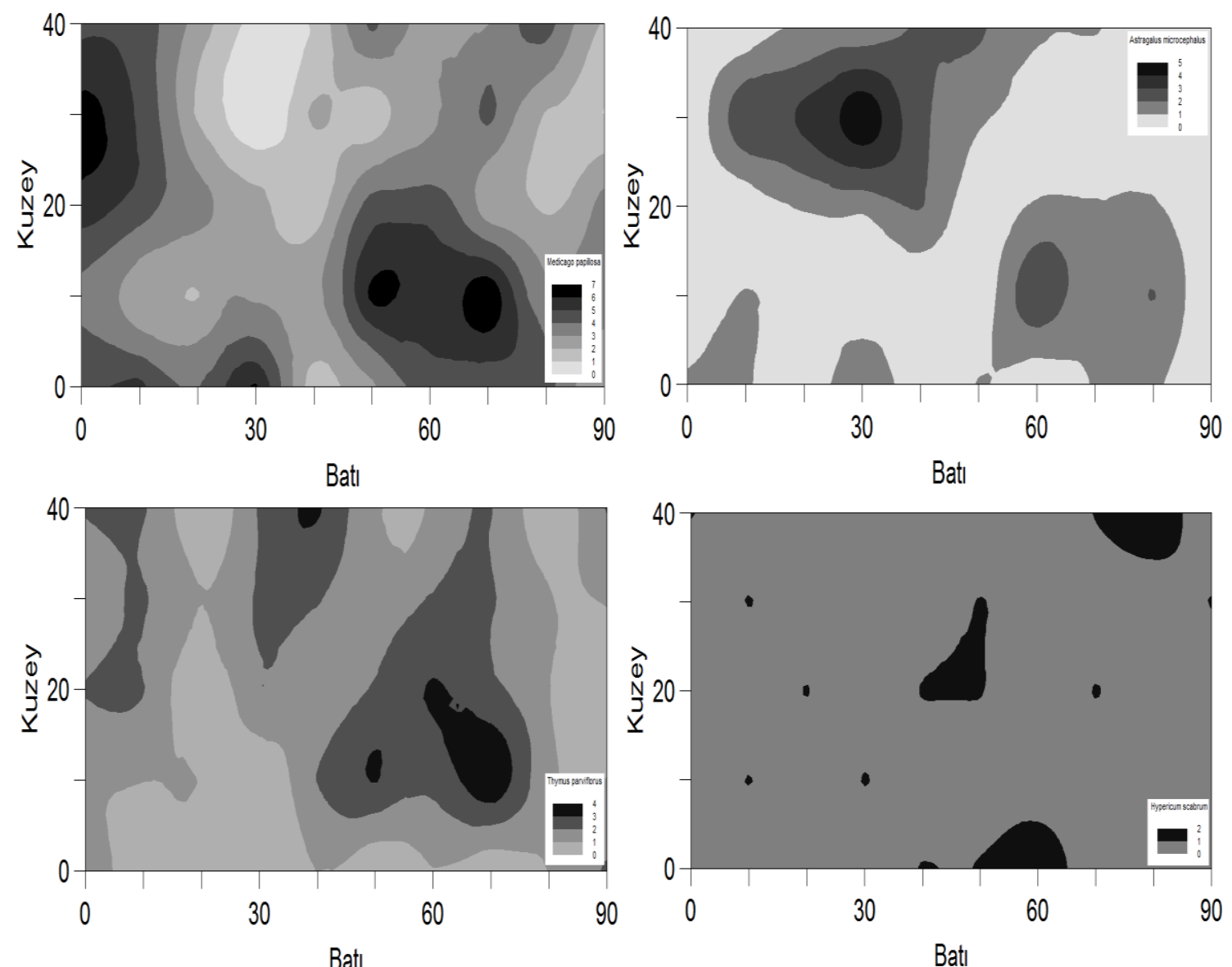

Şekil 1. Geniş yapraklı bitki türlerinin mera vejetasyonlarında batı (x) kuzey (y) ekseninde yersel dağılımları

Bitki türleri heterojen yapıya sahip topraklarda gelişimlerini sürdürerek heterojenliğin artmasına katkıda bulunmaktadırlar (Rajaniemi, 2011). Yüksek rakımlı meralarda toprak yapısının çok değişken olması ve kısa mesafelerde büyük değişiklikler göstermesi (Thilenius, 1979) bu parçalı dağılış üzerine etkili olması beklenen bir durumdur. Doğal bitki örtülerinde türlerinin dağglışları aralarındaki ilişkiye bağlı olarak değişmektedir (Rayburn ve Schupp, 2013). Havanın serbest azotunu 
bağlaması, allelopatik etki göstermesi ve yüksek rakımlı alanlara iyi uyum sağlaması nedeniyle yaşama alanını kendi lehine çevirebilen M. papillosa diğer türlere oranla daha homojen dağılmıştır (Erkovan ve ark. 2008; Eldridge ve ark. 2011; Blaser ve ark. 2013; Sitters ve ark. 2013). Başka bir baklagil bitkisi olan A. microcephalus ise daha çok meralardaki bitki türlerinin yoğunluğunun az olduğu alanlarda yayılış göstermiştir. Zira korunan alanlarda bitkinin azot bağlayarak ortamı zenginleștirmesi nedeniyle gelişen buğdaygiller bu bitkiyi baskı altına almaktadır. Nitekim Erzurum'da yürütülen bir çalışmada azot uygulanan parsellerde dikenli geven türünün hızla azaldığı kaydedilmiştir (Koç ve ark. 1994). Dolayısıyla gölgeye dayanamayan bitki açık alanlarda yaşama şansı bulduğu için buralada kolonileşmiştir. T. parviflorus üretmiş olduğu yeşil aksam ile baklagil türleri kadar olmasa da etrafındaki toprakları besin ve su içerikleri bakımından zenginleştirmekte ve ortamı kendi lehine çevirmektedir (Grant ve ark. 2014; Castanho ve ark. 2015). T. parviflorus'un ortamı kendi lehine çevirmede allelopatik özelliği (Small ve ark. 1990) etkili olmaktadır. Sonuçta bitki kısa boylu olmasına rağmen ortamda yayılış gösterebilmektedir.

Yersel bağımlılık derecesini tanımlamak için nugget varyansın sill varyansa oranı kullanılmıştır. Bu oran \%25'den düşükse çok güçlü, \%25-75 arasında ise orta düzeyde ve $\% 75$ 'den büyükse zayıf yersel bağımlılığın olduğu kabul edilmektedir (Cambardella ve ark. 1994). Yersel değişkenliği incelenen türlerin oranlarının \%25'den düşük olduğu Çizelge 3'de görülmektedir. İncelenen çalışmada baklagil türleri azot bağlama ve üretmiş olduğu atıklarla toprağ iyileştiriken, $T$. parviflorus üretmiş olduğu yeşil aksam ile allelopatik etkisi sayesinde toprak özelliklerini kendi lehine düzenlemektedir, H. scabrum türü ise zayıf gelişmesi ve rekabet gücünün düşük olması nedeniyle alanda daha seyrek bulunmaktadır. Yürütülen bu çalışmada bitki türlerinin bağımlılık derecesinin yüksek olduğu yapılan çalışmalarla benzerlik göstermiştir (Rajaniemi, 2011; Koç ve ark. 2013a; Ehlers ve ark. 2014).

\section{Toprak Özellikleri ve Vejetasyon Arasındaki İlişkikiler}

Toprak özellikleri ile tür kompozisyonu arasında önemli ilişkiler tespit edilmiştir. Tür çevre ilişkisi kümülatif varyans I: 25,0, II: 46,7, III: 65,7 ve IV: 80,2 olarak bulunmuştur. Eigen değerleri ise sırasıyla $0,040,0,035,0,031$ ve 0,023 olarak tespit edilmiş ve toplam inerta 0,161 olarak belirlenmiştir. Bitki türlerinin dağılımı toprak özellikleri ve türler arası ilişkilere bağlı olarak ordinasyon diyagramı üzerinde farklılık göstermektedir (Şekil 2). Organik madde, $\mathrm{P}_{2} \mathrm{O}_{5}$ ile PlaLan, ZizPer ve PolCog, agregat stabilitesi, $\mathrm{NH}_{4}$ ile CarCar, $\mathrm{CaCO}_{3}$ ile AstLin arasında pozitif ve önemli bir ilişki tespit edilmiştir (Şekil 2).

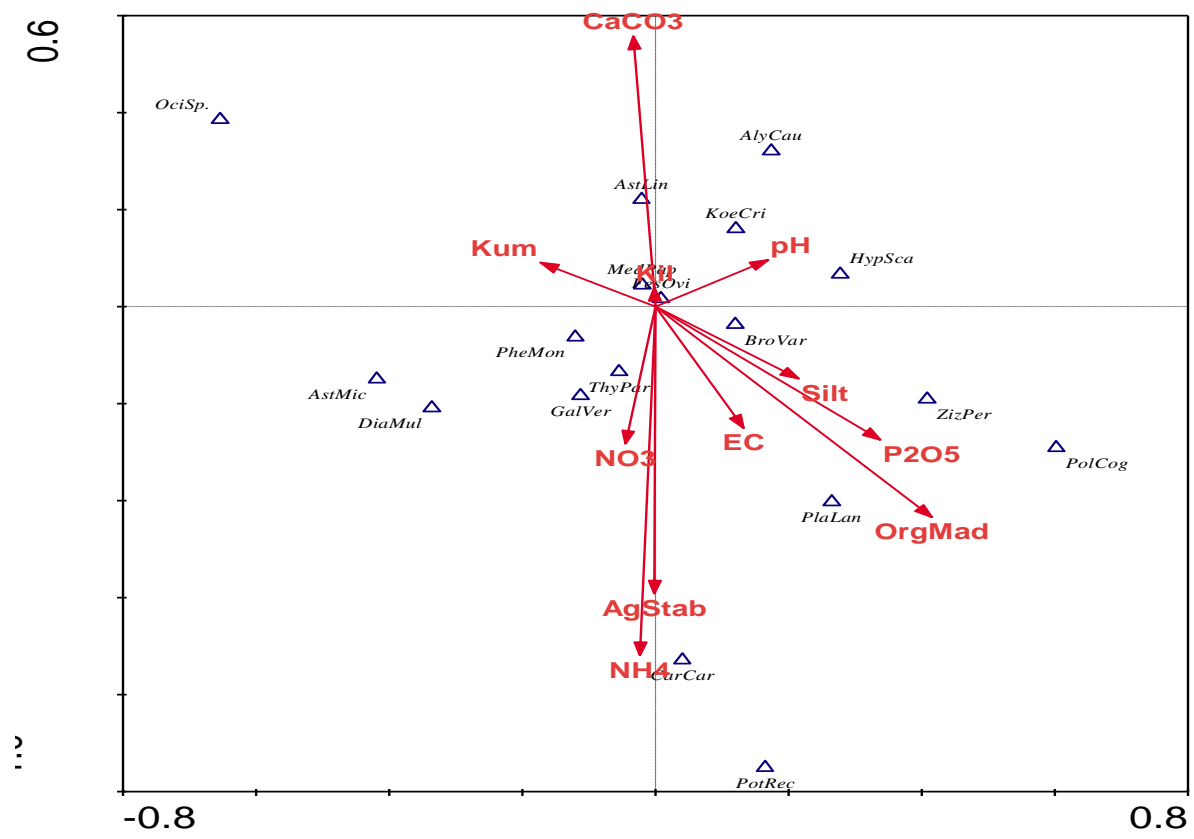

Şekil 2. Araştırma sahası vejetasyon ve toprak özellikleri arasındaki ilişkiler. (Bitki türlerine ait kısaltmalar çizelge 2'de verilmiştir. AgStab: Agregat stabilitesi, OrgMad: Organik madde) 
Aynı iklim, topoğrafya ve kullanım geçmişine sahip meralarda botanik kompozisyonu etkileyen en önemli faktörler toprak özellikleri ile türler arasındaki ilişkilerdir. Organik madde ve besin elementi içeriği tür kompozisyonu ile dağılımını etkileyen önemli faktörlerin başında gelmektedir (Koç ve ark. 2008; Koç ve ark. 2013b; Rayburn and Schupp, 2013). Baklagiller familyasına dahil türlerin yoğun olarak bulunduğu kesimlerde toprakların $\mathrm{Ca}$ içeriği daha yüksektir (Venterink, 2011; Blaser ve ark. 2013). Yeşil aksamı fazla olan bitki türleri çevresinde de toprakların organik madde ve azot içeriğinin daha yüksek olduğu ifade edilmektedir (Erkovan ve ark. 2008; Ehlers ve ark. 2014).

Bitki tür kompozisyonu ve dağılımını etkileyen diğer önemli faktör ise türler arasındaki ilişkilerdir. Bitki türlerinin etkisi doğrudan veya dolaylı olabilmektedir. Doğrudan etki bitkilerin ortamı besin elementi ve su içerikleri açısından zenginleştirmesi şeklinde ortaya çıkarken, dolaylı etki ise aralarındaki rekabet ilişkisi ve mikroorganizma, hayvanlar gibi üçüncü organizmaların etkisiyle ortaya çıkmaktadır (Grant ve ark. 2014; Castanho ve ark. 2015). Doğrudan ve dolaylı etki sonucunda ortam faktörlerindeki değişime bağlı olarak tür kompozisyonu ve dağılışı etkilenmektedir. Diğer önemli bir faktör ise rekabettir. Rekabet gücü yüksek olan türler ortam faktörlerini de kullanarak, tür kompozisyonunu ve dağılımını etkileyebilmektedir (Erkovan ve ark. 2011; Wang ve ark. 2014).

\section{Sonuç}

Sonuç olarak korunan mera vejetasyonlarında bitki türleri üzerine otlatmanın olumsuz etkisi olmamasına karşın, parçalı bir dağılımın ortaya çıkmasında toprak yapısındaki değişim ve türler arası etkileşim etkili olmaktadır. Dolayısıyla bitki türlerinin merada tekdüze bir dağılım göstermesi beklenmez. Ancak yapılacak müdahaleler ile tür bileşeninin değişimi yönlendirilebilir. Zaman içerisinde ortam faktörlerindeki değişime bağlı olarak tür bileşeninde de değişim olması kaçınılmazdır. Elde edilen bulgular Palandöken Dağlarında yüksek rakımlı korunan meralarda zaman içersinde $A$. eriocephalus ve benzeri türlerin gölgeleme etkisi ile oranının azalacağı, $M$. papillasa ve $T$. parviflorus'un artı̧̧ sergileyeceği yönündedir. Bununla birlikte her ne kadar otlatmadan korunsa da ortama yabani hayvanların girmesi durumunda bu türler baskı altına alınabilir. Zira, yaz kuru döneminde yeşil kaldıkları ve otlanabilir olduklarından hayvanlar tarafından tercih edilecektir. Geniş yapraklı türlerin buğdaygiller kadar otlatmaya dayanmadığı dikkate alındığında bu bitkilerin yaz kuru dönemindeki otlatma baskısı ile dağılımlarının düzenlenebileceğini ifade etmemiz mümkündür. Bununla birlikte bu konuda daha detaylı çalışmalara ihtiyaç vardır.

\section{Kaynaklar}

Altın, M., Gökkuş, A., Koç, A., 2011. Çayır ve Mera Yönetimi. T.C. Tarım ve Köyişleri Bakanlığı Tarımsal Üretim ve Geliştirme Genel Müdürlüğü Cilt I, 363 s, Ankara.

Anonim, 2015. T. C. Devlet Meteoroloji İşlerileri Müdürlüğü İklim Verileri.ṣ̌:

Blaser, W.J., Sitters, J., Hart, S.P., Edwards, P.J., Venterink, H.O., 2013. Facilitative or competitive effects of woody plants on understorey vegetation depend on $\mathrm{N}$-fixation, canopy shape and rainfall. Journal of Ecology. 101: 1598-1603.

Cambardella, C.A., Moorman, T.B., Novak, J.M., Parkin, T.B., Karlen, D.L., Turco, R.F., Konopka, A.E., 1994. Field-scale variability of soil properties in central Iowa soils. Soil Science Society of America Journal. 58: 1501-1511: is:

Castanho, C.T., Oliveira, A.A., Prado, P.I.K.L., 2015. Does extreme environmental severity promote plant facilitation? An experimental field test in a subtropical coastal dune. Oecologia. 178: 855-866.

Clarke, P.J., Latz, P.K., Albrecht, D.E., 2005. Long-term changes in semi-arid vegetation: Invasion of an exotic perennial grass has larger effects than rainfall variability. Journal of Vegetation Science. 16: 237-248.

Cramer, M.D., Van Cauter, A., Bond, W.J., 2010. Growth of $\mathrm{N}_{2}$-fixing African savanna Acacia species is constrained by below-ground competition with grass. Journal of Ecology. 98: 156-167.

Ehlers, B.K., Charpentier, A., Grondahl, E., 2014. An allelopathic plant facilitates species richness in the Mediterranean garrigue. Journal of Ecology. 102: 176-185.

Eldridge, D.J., Bowker, M.A., Maestre, F.T., Roger, E., Reynolds, J.F., Whitford, W.G., 2011. Impacts of shrub encroachment on ecosystem structure and functioning: towards a global synthesis. Ecology Letters. 14: 709-722.

Erkovan, H.I., Tan, M., Halitligil, M.B., Kışlal, H., 2008. Performance of white-clover grasses mixtures: Part-I Dry matter production, botanical composition, nitrogen use efficient, nitrogen rate and yield. Asian Journal of Chemistry. 20: 4071-4076. 
Erkovan, H.İ., Koç, A., Aksakal, E.L., Öztaş, T., Özgül, M., 2011. Mera bitki örtüsünün koruma ve farklı otlatma sistemi uygulamalarına tepkisi. Türkiye IX. Tarla Bitkileri Kongresi, 1749-1754. 12-15 Eylül, Bursa.

Friedel, M.H., Pickup, G., Nelson, D.J., 1993. The interpretation of vegetation change in a spatially and temporally diverse arid Australian landscape. Journal of Arid Environments. 24: 241-260.

Gamma Design Software. 2005. GS+Geoistatistics for the Environmental Sciences. GS+ User' s Guide, Ver 7 , Plainwell, USA.

Gökkuş, A., Koç, A., Çomaklı, B., 1995. Çayır - Mera Uygulama Klavuzu. Atatürk Üniversitesi Ziraat Fakültesi Yayınları No: 142, 139 s, Erzurum.

Grant, K., Kreyling, J., Heilmeier, H., Beierkuhnlein, C., Jentsch, A., 2014. Extreme weather events and plantplant interactions: shifts between competition and facilitation among grassland species in the face of drought and heavy rainfall. Ecological Research. 29: 991-1001.

Herbel, C.H., Pieper, R.D., 1991. Grazing Management. In Semiarid Lands and Deserts: Soil Resources and Reclamation, Marcel Dekker, pp. 361-385 New York, USA.

Koç, A., Çomaklı, B., Gökkuş, A., Tahtacıoğlu, L., 1994. Azot ve fosforla gübreleme ile korumanın Güzelyurt Köyü (Erzurum) mer'asının bitki örtüsüne etkileri. Tarla Bitk. Kong.,Cilt III Çayır-Mer'a Yembitk. Bildirileri, 78-82. 25-29 Nisan, İzmir

Koc, A., Erkovan, H.I., Serin, Y., 2008. Changes in vegetation and soil properties under semi-nomadic animal raising areas in highlands, rangelands of Turkey. Current World Environment. 3: 15-20.

Koc, A., Erkovan, S., Erkovan, H.I., Oz, U., Birben, M.M., Tunc, R., 2013a. Competitive effects of plant species under different sowing ratios in some annual cereal and legume mixtures. Journal of Animal and Veterinary Advances. 12: 509-520.

Koç, A. Güllap, M.K., Erkovan, H.I., 2013b. The soil seed bank pattern in highland rangelands of Eastern Anatolian Region of Turkey under different garzing systems. Turkish Journal of Field Crops. 18: 109117.

Kurokawa, H., Peltzer, D.A., Wardle, A., 2010. Plant traits, leaf palatability and litter decomposability for cooccurring woody species differing in invasion status and nitrogen fixation ability. Functional Ecology. 24: $513-523$.

Lauenroth, W.K., 1979. Grassland primary production: North American grassland in perspective, In perspectives in grasslans ecology, Ed: N.R. French. Springer-Verlag, New York. 3-24.

Lund, H.G., 2007. Accounting for the world's rangelands. Rangelands. 29: 3-10.

Rajaniemi, T.K., 2011. Competition for patchy soil resources reduces community evenness. Oecologia. 165: 169-174.

Rayburn, A.P., Schupp, E.W., 2013. Effects of community- and neighborhood-scale spatial patterns on semi-arid perennial grassland community dynamics. Oecologia. 172: 1137-1145.

Sitters, J., Edwards, P.J. Venterink, H.O., 2013. Increases of soil C, N and P pools along an Acacia tree density gradient and their effects on trees and grasses. Ecosystems. 16: 347-357.

Small, E., Jurzysta, M. Nozzolillo C., 1990. The evolution of hemolytic saponin content in wild and cultivated Alfalfa (Medicago sativa, Fabaceae). Economic Botany. 44: 226-235.

Soil Survey Laboratory Staff., 1992. Soil Survey Laboratory Methods Manual. USDA-SCS. Soil Survey Investigations Report No: 42.

ter Braak, C.F.J., Smilauer, P., 2002. Canoco Reference Manueal and Candraw for Windows User's Guide: Software for Canonical Community Ordination (Version 4.5). Wageningen University and Research Centre, Wageningen.

Thilenius J. F., 1979. Range management in the alphin zone: Practices and Problems. In: Special Managements Needs of Alpine Ecosystems (Ed: D. A. Johnson). Soc. Range Manage., Range Sci. Series No: 5 Colorado, USA.

Venterink, H.O., 2011. Does phosphorus limitation promote species-rich plant communities?. Plant Soil. 345: 19.

Verdu, M., Jordano, P., Valiente-Banuet, A., 2010. The phylogenetic structure of plant facilitation networks changes with competition. Journal of Ecology. 98: 1454-1461.

Wang, P., Weiner, J., Cahill, J.F., Zhou, D.W., Bian, H.F., Song, Y.T., Sheng, L.X., 2014. Shoot competitşon, root competition and reproductive allocation in Chenopodium acuminatum. Journal of Ecology. 102: $1688-1696$ 